\title{
Non-Invasive Colorimetric Magneto Loop-Mediated Isothermal Amplification (CM-LAMP) Method for Helicobacter pylori Detection
}

\author{
Khotchawan Bangpanwimon ${ }^{1}$, Pimonsri Mittraparp-arthorn ${ }^{1,2}$, Kanchana Srinitiwarawong1, \\ and Natta Tansila ${ }^{3 *}$ \\ 'Department of Microbiology, Division of Biological Science, Faculty of Science, Prince of Songkla University, Hat- \\ Yai, Songkhla 90110, Thailand \\ ${ }^{2}$ Molecular Evolution and Computational Biology Research Unit, Faculty of Science, Prince of Songkla University, \\ Hat-Yai, Songkhla 90110, Thailand \\ ${ }^{3}$ Faculty of Medical Technology, Prince of Songkla University, Hat-Yai, Songkhla 90110, Thailand
}

\begin{abstract}
More than half the world's population is thought to be infected with Helicobacter pylori. Although the majority of infected people are asymptomatic, $H$. pylori infection may cause gastric ulcers and deadly gastric cancer. Owing to the difficulty and invasiveness of current routine culture and diagnostic methods, a highly sensitive and specific noninvasive assay for $H$. pylori is of interest. This study highlighted the design and performance of a colorimetric magneto loop-mediated isothermal amplification (CM-LAMP) assay to detect $\boldsymbol{H}$. pylori in spiked saliva samples. LF primers were coated on magnetic nanoparticles by carbodiimide-induced immobilization and functionally used for solidphase amplification. During the LAMP reaction at $66^{\circ} \mathrm{C}$, biotin-tagged FIPs were incorporated into LAMP amplicons. The colorimetric signal developed after the addition of NeutrAvidin horseradish peroxidase conjugate (NA-HRP) and ABTS. None of the tested microorganisms, including closely related bacteria, was shown positive by the CM-LAMP assay except $H$. pylori isolates. This novel platform was highly specific and 100 -fold more sensitive ( $40 \mathrm{CFU} / \mathrm{ml}$ or $0.2 \mathrm{CFU}$ per reaction) than the PCR and conventional LAMP assays for the detection of $H$. pylori in spiked saliva. Our results demonstrated the feasibility of using this noninvasive molecular diagnostic test to detect $H$. pylori in saliva samples.
\end{abstract}

Keywords: Loop-mediated isothermal amplification (LAMP), colorimetric magneto LAMP assay (CM-LAMP), magnetic nanoparticles (MNPs), Helicobacter pylori, non-invasive test, saliva

Received: January 7, 2021 Accepted: February 22, 2021

First published online: February 25, 2021

* Corresponding author Phone: +66-74-289106 Fax: $+66-74-289101$ E-mail: natta.t@psu.ac.th

pISSN 1017-7825 eISSN 1738-8872

Copyright(C) 2021 by The Korean Society for Microbiology and Biotechnology

\section{Introduction}

Helicobacter pylori is one of the bacterial species classified by the International Agency for Research on Cancer (IARC) as a Group 1 carcinogen [1]. This bacterium is a causative agent of peptic ulcer and gastric cancers. It is well adapted to the human organism and has been isolated from more than half the people in the world. The route of $H$. pylori transmission remains questionable but the most probable paths are the oral-oral route via saliva and vomit and the fecal-oral route [2].

The techniques for $H$. pylori detection can be divided into two categories depending on the use of endoscopy for gastric biopsy collection. Histology, culture, and the rapid urease test (RUT) are considered invasive methods, while the urea breath test (UBT), the stool antigen test (SAT), serological testing, and molecular techniques that use samples of saliva or feces are considered noninvasive methods [3].

Invasive methods require experienced and skilled personnel, and detection depends heavily on the concentration of microorganisms. Also, several oral and gastric flora, such as Proteus mirabilis, Klebsiella pneumoniae, and Staphylococcus aureus, exhibit urease activity and can generate false-positive results in the RUT and UBT $[4,5]$. Moreover, $H$. pylori becomes viable but not culturable (VBNC) in non-suitable conditions, leading to falsenegative results $[6,7]$. Also, the efficiency of antigen detection by the SAT was adversely affected as a result of diluted targets in watery stool samples [8]. The serology test has lower specificity and sensitivity than other methods and its positivity may not indicate a current active infection [9]. Although several molecular techniques, mostly based on PCR, have been reported, they often had problems of limited sensitivity resulting from PCR inhibitors as well as low numbers of $H$. pylori, especially in stool and saliva samples $[10,11]$. 


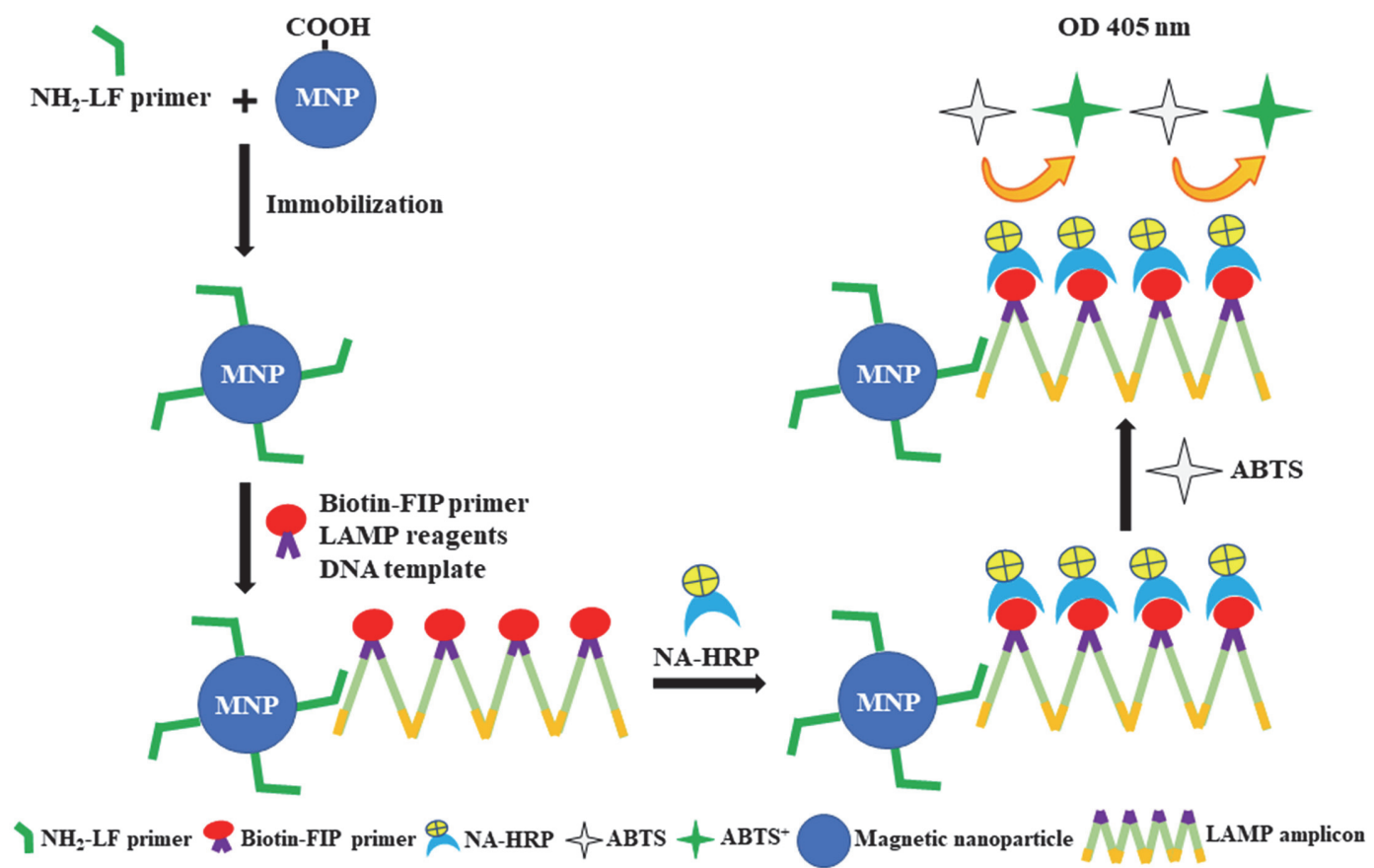

Fig. 1. Schematic diagram of the colorimetric magneto-LAMP (CM-LAMP) assay. The carboxylated magnetic nanoparticles (MNPs) were immobilized with the amino-modified LF primer $\left(\mathrm{NH}_{2}\right.$-LF primer) using the carbodiimide method. During amplification at $66^{\circ} \mathrm{C}$, the MNP-conjugated LF primer annealed and amplified the target gene, and the biotinlabeled LAMP amplicons were then produced. After that, the amplicons were mixed with NeutrAvidin- horseradish peroxidase conjugate (NA-HRP), and an ABTS (colorless) substrate was subsequently added to generate the blue-green $\mathrm{ABST}^{+}$products. The optical density (OD) of the colorimetric signal was measured at $405 \mathrm{~nm}$.

Bearing in mind the difficulties of cultivation and the invasiveness of currently-used diagnostic procedures, a sensitive and specific noninvasive method of detecting $H$. pylori in saliva samples is of interest. In this work we aimed to improve the efficacy of analysis by incorporating the known advantages of loop-mediated isothermal amplification (LAMP), magnetic nanoparticles (MNPs), and a colorimetric system. The low abundance of $H$. pylori in saliva was overcome by the specificity and high sensitivity of LAMP [12]. A colorimetric system was previously used to increase the accuracy and reliability of LAMP product measurement [13] and the selective enrichment of LAMP products was facilitated by the superparamagnetism and biocompatibility of MNPs $[14,15]$. Against this background, we present for the first time the design of an MNP-LAMP-colorimetric system, the socalled colorimetric magneto (CM)-LAMP assay, to detect low numbers of $H$. pylori in saliva. A schematic diagram of the novel system was presented in Fig. 1.

\section{Materials and Methods}

Isolation, Identification, and Confirmation of $H$.pylori

This study was approved by the Office of Human Research Ethics Committee (HREC), Prince of Songkla University (EC: 58-241-19-2). Between August 2015 and June 2016, residual gastric biopsy specimens were obtained from dyspepsia patients at the NKC Institute of Gastroenterology and Hepatology, Songklanagarind Hospital, Prince of Songkla University. The samples were transferred into brain heart infusion (BHI) transport media with 2,500 IU/L polymyxin B, $5 \mu \mathrm{g} / \mathrm{ml}$ trimethoprim, and $10 \mu \mathrm{g} / \mathrm{ml}$ each of vancomycin and amphotericin B. They were inoculated on Columbia agar supplemented with $7 \%$ sheep blood (Oxoid, UK) and incubated at $37^{\circ} \mathrm{C}$ under microaerophilic conditions for 3-7 days. H. pylori was identified based on colony morphology (0.5$1.5 \mathrm{~mm}$ pinpoint and translucent with slight hemolysis) and biochemical testing (urease-, catalase-, and oxidasepositive). Finally, the typical colony was subjected to confirmation by PCR assay to amplify a 294-bp fragment of the housekeeping $g l m M$ genes of $H$. pylori as previously described [16].

\section{LAMP Assay}

LAMP primer design. The DNASTAR software was used to perform multiple alignments of $16 S$ rRNA sequences of $10 \mathrm{H}$. pylori strains (26695, J99, OK310, SJM180, v225d, HPAG1, XZ274, 51, 908 and 2018) against those of H. mustelae, H. heilmannii, W. succinogenes, C. jejuni, C. coli, P. mirabilis, U. urealyticum, K. pneumoniae, M. morganii, N, meningitidis, E. coli, V. parahaemolyticus, and V. cholerae. Using the PrimerExplorer v4.0 software, a set of LAMP primers was designed to selectively target a highly conserved region (Table 1). The obtained primers were analyzed by the nucleotide BLAST tool to ensure specificity, and primer-dimer and hairpin loop formation were checked by vector NTI software. 
Table 1. Primers used for conventional LAMP and CM-LAMP assays for $H$. pylori detection.

\begin{tabular}{llc}
\hline Primer name & \multicolumn{1}{c}{ Primer Sequence (5' to 3') } & Length (bp) \\
\hline 16 s HP-F3 & TGCTAACAGGTYATGCTGAG & 20 \\
16 s HP-B3 & GCAACATGGCTGATTTGCG & 19 \\
16s HP-FIP & TAGCCCTAGGCGTAAGGGCCCTGCCTCCGTAAGGAGGAG & 39 \\
16s HP-BIP & ACTGCGAAGTGGAGCCAATCTTGCTTCATGCAGGCGAGTT & 40 \\
16 s HP-LF $^{\mathrm{b}}$ & TTGACGTCGTCCCCACCTTC & 20 \\
$16 \mathrm{~s} \mathrm{HP}-L B^{\mathrm{s}}$ & ACACCTCTCAGTTCGGATTGTAGG & 24 \\
\hline
\end{tabular}

${ }^{a}$ For CM-LAMP assay, 16s HP-FIP primer was labeled with biotin at 5 ' end.

${ }^{b}$ For CM-LAMP assay, 16s HP-LF primer was modified with $\mathrm{NH}_{2}-\mathrm{C}_{12}$ at 5 'end.

LAMP condition. The LAMP assay was performed in a final volume of $25 \mu \mathrm{l}$ comprising $5 \mu \mathrm{l}$ of extracted DNA, $0.25 \mu \mathrm{M}$ of primer F3, $0.2 \mu \mathrm{M}$ of primer B3, $1.6 \mu \mathrm{M}$ of primers FIP and BIP, $0.8 \mu \mathrm{M}$ of primers LF and LB, $8 \mathrm{U}$ of $B s t$ DNA polymerase (New England Biolabs, USA), $0.8 \mathrm{M}$ betaine solution (Sigma-Aldrich, USA), $8 \mathrm{mM} \mathrm{MgSO}_{4}$ and $1.4 \mathrm{mM}$ dNTPs in LAMP 4 mix buffer (20 mM Tris-HCl, pH8.8), $10 \mathrm{mM} \mathrm{KCl,} 10 \mathrm{mM}\left(\mathrm{NH}_{4}\right)_{2} \mathrm{SO}_{4}$, and $0.2 \%$ Tween 20. The reaction mixture was incubated in the Loopamp Realtime Turbidimeter (Eiken Chemical, Japan) for $35 \mathrm{~min}$ at $66^{\circ} \mathrm{C}$ and inactivated for $2 \mathrm{~min}$ at $80^{\circ} \mathrm{C}$. The reaction was judged as positive when turbidity reached 0.1 within $35 \mathrm{~min}$.

\section{Specificity and Sensitivity of the LAMP Assay in Pure Culture}

The specificity of the designed LAMP primers was evaluated using pure cultures of H. pylori, Campylobacter spp., and urease-positive and pathogenic bacteria commonly found in the oral and enteric cavities (Table 2). A typical colony of each bacterium was boiled for $10 \mathrm{~min}$ in $300 \mu \mathrm{l}$ of DI water. After centrifugation at $20,000 \mathrm{~g}, 4^{\circ} \mathrm{C}$ for $10 \mathrm{~min}$, the supernatant was collected and used as the DNA template. For sensitivity testing, the H. pylori culture was adjusted to $10^{7} \mathrm{CFU} / \mathrm{ml}$ and tenfold dilution was performed to obtain a range of bacterial concentrations from $4 \times 10^{1}$ to $4 \times 10^{5} \mathrm{CFU} / \mathrm{ml}$. Bacteria were enumerated by drop plate technique [17]. A PCR specific to the $g \operatorname{lm} M$ gene was conducted and the results were compared with the results of LAMP. Concentration testing was performed in triplicate and the limit of detection (LOD) was described as the lowest bacterial concentration giving positive results in all three replicates.

\section{Sensitivity of the LAMP Assay in Spiked Saliva}

Saliva from healthy individuals was collected and tested for the absence of H. pylori by glmM-specific PCR. Saliva confirmed free of the bacterium was then inoculated with $H$. pylori at final concentrations ranging from $4 \times 10^{1}$ to $4 \times 10^{5} \mathrm{CFU} / \mathrm{ml}$. DNA templates from spiked saliva were prepared by Presto Mini gDNA Bacteria Kit

Table 2. Specificity of $H$. pylori detection by conventional LAMP assay.

\begin{tabular}{|c|c|c|c|}
\hline \multirow{2}{*}{ Bacteria } & \multirow{2}{*}{ No. of isolates } & \multicolumn{2}{|c|}{ Conventional LAMP assay } \\
\hline & & + & - \\
\hline \multicolumn{4}{|l|}{ Campylobacterales } \\
\hline Helicobacter pylori & 7 & 7 & 0 \\
\hline Campybacter jejuni & 5 & 0 & 5 \\
\hline Campybacter coli & 2 & 0 & 2 \\
\hline Campybacter lari & 1 & 0 & 1 \\
\hline \multicolumn{4}{|l|}{ Oral bacteria } \\
\hline Streptococcus mutans DMST 1877 & 1 & 0 & 1 \\
\hline \multicolumn{4}{|l|}{ Urease +ve bacteria } \\
\hline Staphylococcus aureus DMST 20654 & 1 & 0 & 1 \\
\hline Neisseria meningitidis & 1 & 0 & 1 \\
\hline Klebsiella pneumoniae & 1 & 0 & 1 \\
\hline Proteus mirabilis & 1 & 0 & 1 \\
\hline Providensia rettgeri & 1 & 0 & 1 \\
\hline Citrobacter freundii & 1 & 0 & 1 \\
\hline \multicolumn{4}{|l|}{ Enteric bacteria } \\
\hline Shigella boydii & 1 & 0 & 1 \\
\hline Shigella flexneri & 1 & 0 & 1 \\
\hline Aeromonas hydrophila & 1 & 0 & 1 \\
\hline Salmonella Paratyphi & 1 & 0 & 1 \\
\hline Salmonella Enteritidis & 1 & 0 & 1 \\
\hline Vibrio paraheamolyticus & 1 & 0 & 1 \\
\hline Vibrio cholerae ATCC 39315 & 1 & 0 & 1 \\
\hline Escherichia coli ATCC 8739 & 1 & 0 & 1 \\
\hline Pseudomonas aeruginosa ATCC 27853 & 1 & 0 & 1 \\
\hline
\end{tabular}


(Geneaid Biotech, Taiwan) and subjected to both $g \operatorname{lm} M$-specific PCR and LAMP assay for sensitivity analyses. Triplicate experiments were applied to all concentration testing and the LOD was obtained as described above.

Colorimetric Magneto (CM)-LAMP Assay

Immobilization of primers onto MNPs. Carboxylated MNPs (Chemicell GmbH, Germany) were coated with $\mathrm{NH}_{2}$-modified LF primer using the carbodiimide method [18]. In brief, stock MNPs $(25 \mathrm{mg} / \mathrm{ml})$ were activated by sonication at $30 \%$ amplitude for $10 \mathrm{~min}$. The activated MNPs $(0.2 \mathrm{mg})$ were washed with $200 \mu \mathrm{l}$ of 2-(Nmorpholino)ethanesulfonic acid (MES) buffer $(25 \mathrm{mM}, \mathrm{pH}$ 6.0) until the supernatant was clear. They were then mixed with $\mathrm{NH}_{2}$-modified LF primer (1-2.5 nmol) and incubated for $30 \mathrm{~min}$ at room temperature under gentle shaking, after which $16 \mu \mathrm{l}$ of 1-ethyl-3-(3dimethylaminopropyl) carbodiimide (EDC) solution $(10 \mathrm{mg} / \mathrm{ml}$ ) were added. After overnight incubation at $4^{\circ} \mathrm{C}$ under gentle shaking, the supernatant was collected. Using the MaestroNano spectrophotometer (Maestrogen, Taiwan), the absorbance of the supernatant was measured at $260 \mathrm{~nm}$, which represented the residual concentration of $\mathrm{NH}_{2}$-modified LF primer. Following a previously described method [19], the concentration of immobilized LF primer on MNPs (Q value, nmol of primers/mg of MNPs) was determined and calculated from the formula $\mathrm{Q}=\left[\left(\mathrm{C}_{\mathrm{o}}-\mathrm{C}_{\mathrm{e}}\right) \times \mathrm{V}\right] /(\mathrm{M} \times \mathrm{m})$, where $\mathrm{Q}$ is the primer immobilization efficiency (nmol primer/mg MNPs), $\mathrm{C}_{\mathrm{o}}$ and $\mathrm{C}_{\mathrm{e}}$ are the initial and residual primer concentrations $(\mathrm{ng} / \mu \mathrm{l}), \mathrm{M}$ is the molecular weight of oligonucleotide $(\mathrm{ng} / \mathrm{nmol}), \mathrm{m}$ is the mass of MNPs $(\mathrm{mg})$, and $\mathrm{V}$ is the volume of solution $(\mu \mathrm{l})$. The primer-immobilized MNPs were mixed with Tris buffer ( $50 \mathrm{mM}, \mathrm{pH} 7.4$ ) to quench the unreacted carboxyl groups. The quenching step was repeated twice. Finally, the primer-immobilized MNPs were re-suspended in $100 \mu \mathrm{l}$ of Tris-EDTA buffer (10 mM Tris- $\mathrm{HCl}$ and $1 \mathrm{mM}$ EDTA, $\mathrm{pH} 8.0)$ and stored at $4^{\circ} \mathrm{C}$ until used.

Immobilization efficiency testing of primer-coated MNPs. The efficiency of LF primer-coupled MNPs was analyzed by the hybridization technique previously indicated [20]. Briefly, $5 \mu \mathrm{l}$ of LF primer-immobilized MNPs $(2 \mu \mathrm{g} / \mu \mathrm{l})$ was washed twice with $100 \mu \mathrm{l}$ of phosphate-buffered saline (PBS) buffer (pH 7.4). Then, $2 \mu \mathrm{l}$ of $10 \mu \mathrm{M}$ complementary LF primer tagged with biotin (5'-biotin-GAAGGTGGGGACGACGTCAA-3') in 13×salinesodium citrate (SSC) buffer was added and the MNPs were incubated at RT for 30 min under gentle shaking. The MNPs were washed twice with $150 \mu \mathrm{l}$ of PBS containing $1 \%$ bovine serum albumin (BSA) and then incubated in darkness with $2.5 \mu \mathrm{l}$ of NeutrAvidin horseradish peroxidase conjugate (NA-HRP) $(0.01 \mathrm{mg} / \mathrm{ml}$ ) (Thermo Scientific, USA) in PBS buffer at RT under gentle shaking for $30 \mathrm{~min}$. After washing twice with PBS buffer, $50 \mu \mathrm{l}$ of 2,2'-Azino-bis (3-ethylbenzthiazoline-6-sulfonic acid) (ABTS) (Merck KGaA, Germany) containing $\mathrm{H}_{2} \mathrm{O}_{2}$ in a citrate buffer ( $\mathrm{pH}$ 4.0) was added and incubated in darkness at RT under gentle shaking for $30 \mathrm{~min}$. HRP activity was measured spectrophotometrically at $405 \mathrm{~nm}$ using a microplate reader (BMG Labtech, Germany). DI water and uncoupled MNPs were used as negative controls.

\section{CM-LAMP Assay}

The CM-LAMP assay was performed in $25 \mu \mathrm{l}$ containing $5 \mu \mathrm{g}$ of LF primer-immobilized MNPs, $0.25 \mu \mathrm{M}$ of primer F3, $0.2 \mu \mathrm{M}$ of primer B3, $0.8 \mu \mathrm{M}$ of primer LB, 1.6 $\mu \mathrm{M}$ of primer BIP and biotin-labeled FIP (Table 1), $5 \mu \mathrm{l}$ of extracted DNA, $8 \mathrm{U}$ of Bst DNA polymerase, and $12.5 \mu \mathrm{l}$ of $2 \times$ Reaction Mix Loopamp DNA Amplification Kit (Eiken Chemical, Japan). The reaction mixture was incubated in the Loopamp Realtime Turbidimeter for $50 \mathrm{~min}$ at $66^{\circ} \mathrm{C}$ and was then inactivated for $2 \mathrm{~min}$ at $80^{\circ} \mathrm{C}$. MNP-LAMP-Biotin products were measured using a colorimetric end-point system. Reactions were treated with $150 \mu \mathrm{l}$ of $1 \% \mathrm{BSA}$ solution for $1 \mathrm{~h}$ at $37^{\circ} \mathrm{C}$ and incubated in darkness with $2.5 \mu \mathrm{l}$ of NA-HRP $(0.01 \mathrm{mg} / \mathrm{ml})$ in PBS buffer at RT under gentle shaking for $30 \mathrm{~min}$. After washing the reaction products twice with PBS buffer, $50 \mu$ of ABTS (containing $\mathrm{H}_{2} \mathrm{O}_{2}$ ) in a citrate buffer $(\mathrm{pH}$ 4.0) was added and the products were incubated in darkness at RT under gentle shaking for 30 min. HRP activity was measured at $405 \mathrm{~nm}$ using the microplate reader.

\section{Specificity and Sensitivity of CM-LAMP Assay in Pure Culture and Spiked Saliva}

The specificity of the CM-LAMP assay was evaluated using pure cultures of 19 clinical isolates of H. pylori, Campylobacter spp., urease-positive bacteria, and commensal bacteria. The sensitivity of the CM-LAMP assay was evaluated using the extracted DNA template from pure cultures and spiked saliva using the methods described previously. The cut-off value of a positive result was derived from the formula NC $+3 \mathrm{SE}$ in which NC and $\mathrm{SE}$ are the averages and standard error of $\mathrm{OD}_{405 \mathrm{~nm}}$ from negative controls $[20,21]$. The $\mathrm{SE}$ of the mean values was shown as a thin line above the bars.

\section{Results}

\section{Characteristics of $H$. pylori Isolates}

A total of 50 gastric biopsy samples were collected from Songklanagarind Hospital. Seven isolates of $H$. pylori from dyspepsia patients were identified by biochemical tests and from $g \operatorname{lm} M$-specific PCR and used in primer specificity testing. One of the isolates was sequenced for $16 \mathrm{~s}$ rRNA gene and used as an experimental strain in sensitivity testing. It possessed $98 \%$ identity to $H$. pylori strain ML2 at E-value 0 (data not shown).

\section{Conventional LAMP and PCR Assays}

In this study, LAMP primers were designed based on a unique region of the $16 S r R N A$ gene of $H$. pylori (Table 1 ). The evaluation of LAMP specificity was based on DNA samples isolated from pure cultures of 7 isolates of H. pylori, 5 isolates of Campylobacter jejuni, 2 isolates of Campylobacter coli, 1 isolate of Campylobacter lari, and 15 isolates of urease-positive and pathogenic bacteria found in the oral and enteric cavities. As demonstrated in 
Table 3. Limit of $H$. pylori detection by PCR, LAMP and CM-LAMP assays.

\begin{tabular}{|c|c|c|c|c|c|c|c|}
\hline \multirow{3}{*}{ Sample } & \multirow{3}{*}{ Assay } & \multicolumn{5}{|c|}{ Results (positive reactions/numbers tested) } & \multirow[b]{2}{*}{$\mathrm{CFU} / \mathrm{ml}$} \\
\hline & & $4 \times 10^{5}$ & $4 \times 10^{4}$ & $4 \times 10^{3}$ & $4 \times 10^{2}$ & $4 \times 10^{1}$ & \\
\hline & & $2 \times 10^{3}$ & $2 \times 10^{2}$ & $2 \times 10^{1}$ & $2 \times 10^{0}$ & $2 \times 10^{-1}$ & CFU/reaction \\
\hline \multicolumn{8}{|c|}{ Pure culture } \\
\hline & PCR & + & + & + & $\pm(1 / 3)$ & - & \\
\hline & LAMP & + & + & + & + & - & \\
\hline & CM-LAMP & + & + & + & + & + & \\
\hline \multicolumn{8}{|c|}{ Spiked saliva } \\
\hline & PCR & + & + & + & - & - & \\
\hline & LAMP & + & + & + & $\pm(1 / 3)$ & - & \\
\hline & CM-LAMP & + & + & + & + & + & \\
\hline
\end{tabular}

$+=$ Positive in all triplicate experiments.

- = Negative in all triplicate experiments.

$\pm=$ Variable detection in triplicate experiments (positive reactions/numbers tested).

Table 2, all $H$. pylori isolates could be detected by our designed LAMP primers, while other isolates generated true negative results. LAMP detected $H$. pylori as low as $2 \mathrm{CFU}$ per reaction or $400 \mathrm{CFU} / \mathrm{ml}$ in pure culture, which was 10 -fold lower than the quantity detected by PCR $(20 \mathrm{CFU}$ per reaction or $4,000 \mathrm{CFU} / \mathrm{ml}$ in pure culture) (Table 3 ). Both LAMP and PCR assays gave consensus positivity for detection of $20 \mathrm{CFU}$ of $\mathrm{H}$. pylori in spiked saliva, (Table 3). It is worth noting that one-third of triplicate experiments of LAMP and PCR assays were positive at $2 \mathrm{CFU}$ per reaction assay in both spiked saliva and pure culture (Table 3 ).

\section{CM-LAMP Assay}

Preparation and assessment of primer-immobilized MNPs. LF primers with 5 '- $\mathrm{NH}_{2}$ modification were immobilized onto the MNP surface by the carbodiimide method. After the coating steps, the absorbance of the supernatant was recorded at $260 \mathrm{~nm}$. The amount of $\mathrm{NH}_{2}$-modified LF primer to be immobilized on the surface of the MNPs $(\mathrm{Q})\left(\mathrm{nmol} / \mathrm{mg}\right.$ ) was calculated. Increasing the initial concentration of $\mathrm{NH}_{2}$-modified LF primers up to $2 \mathrm{nmol}$ resulted in a higher $\mathrm{Q}$ value (Fig. 2). However, the $\mathrm{Q}$ value decreased when the initial concentration of the LF primer reached $2.5 \mathrm{nmol}$. To obtain efficient DNA amplification, the primer-immobilized MNPs prepared from an initial concentration of $2 \mathrm{nmol} \mathrm{NH}_{2}$-modified LF were employed in subsequent CM-LAMP assays. Thus, the obtained reagent had an LF primer density of $3.66 \pm 0.33 \mathrm{nmol} / \mathrm{mg}$ MNPs (Fig. 2). A hybridization approach was used to ensure the completion of the primer-coupling reaction and the presence of LF primers on the surface of the MNPs. The biotinylated complementary primer could anneal to LF primers coated on the MNPs and give rise to an HRP-catalyzed colorimetric reaction (Fig. 3). The absorbance of this reaction was approximately 2 -fold higher than that of the reaction without the complementary primer. The highest absorbance was found when uncoupled MNPs were used. This finding indicated the non-specific adsorption of MNPs, which was overcome by the addition of a blocking solution (1\% BSA), as illustrated in Fig. 3. Therefore, these findings indicated that the LF-immobilized MNPs and other colorimetric reagents were possibly functional in the CM-LAMP assay for the detection of H. pylori.

Efficiency of CM-LAMP assay for $\boldsymbol{H}$. pylori detection in pure culture and spiked saliva. The specificity of the CM-LAMP assay was determined using extracted genomic DNA of 19 clinical isolates of $H$. pylori, Campylobacter

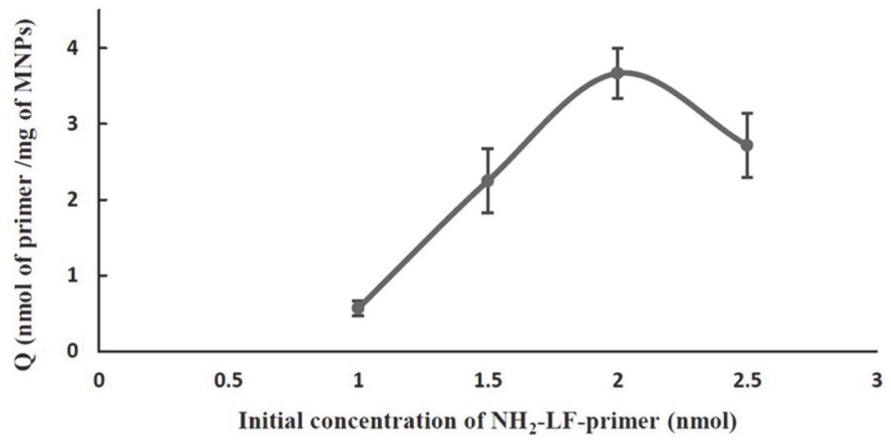

Fig. 2. The initial concentration of $\mathrm{NH}_{2}$-modified $\mathrm{LF}$ primers immobilized on MNPs was varied from $1 \mathrm{nmol}$ to $2.5 \mathrm{nmol}$. The MNPs $(0.2 \mathrm{mg})$ were mixed with the primer concentration and incubated at $4^{\circ} \mathrm{C}$ overnight. The supernatant was collected to measure the residual concentration of the primers. The $Q$ value of the immobilized LF primers on MNPs was determined from the following formula: $\mathrm{Q}=\left[\left(\mathrm{C}_{\mathrm{o}}-\mathrm{C}_{\mathrm{e}}\right) \times \mathrm{V}\right] /(\mathrm{M} \times \mathrm{m})$ where $\mathrm{Q}$ is the efficiency of the primer immobilization (nmol primer/mg MNPs), $\mathrm{C}_{\mathrm{o}}$ and $\mathrm{C}_{\mathrm{e}}$ are the initial and residual primer concentrations ( $\left.\mathrm{ng} / \mu \mathrm{l}\right), \mathrm{M}$ is the molecular mass of the primer ( $\mathrm{ng} / \mathrm{nmol}), \mathrm{m}$ is the mass of MNPs $(\mathrm{mg})$, and $\mathrm{V}$ is the volume of solution $(\mu \mathrm{l})$. 


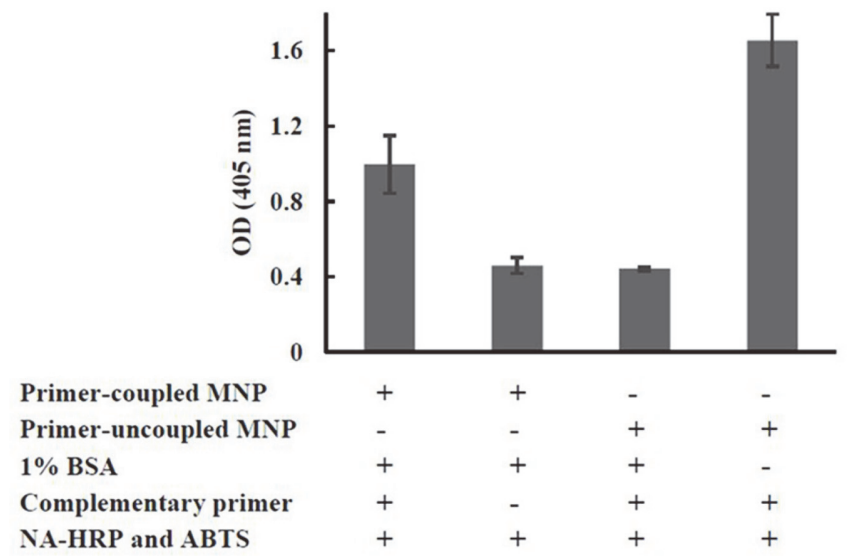

Fig. 3. The hybridization of the biotinylated-complementary oligonucleotide to LF primer was used to analyze the efficiency of LF primer immobilization on the surface of MNPs. Bovine serum albumin (1\% BSA) was added to reduce the non-specific adsorption of complementary primer on the surface of MNPs. After the addition of enzyme conjugate and substrate, the colorimetric signal of $\mathrm{ABTS}^{-+}$was measured at $405 \mathrm{~nm}$. Reactions mixed with DI water or primeruncoupled MNPs were recorded to evaluate the background absorbance. All experiments were done in triplicate and the means and SE values were plotted.

spp., urease-positive and commensal bacteria. The cut-off value was obtained from the determination of the reactions with no genomic DNA and calculated by the NC + 3SE formula mentioned earlier. The data in Fig. 4 revealed that true-positive results were obtained only from $H$. pylori isolates (relative absorbance above cut-off value), and neither false-positive nor false-negative results were obtained from the CM-LAMP assay. The genomic DNA of $H$. pylori was 10 -fold serially diluted and analyzed by CM-LAMP assay. Fig. 5A showed that the relative $\mathrm{OD}_{405 \mathrm{~nm}}$ values for $H$. pylori were $1.43 \pm 0.07,2.22 \pm 0.15,2.40 \pm 0.15,2.17 \pm 0.10,2.26 \pm 0.03$, and $2.45 \pm 0.30$. These values are equivalent to $0,0.2,2,20,200$ and 2,000 CFU per reaction, respectively. These were all above the cut-off value of 1.64 (dash line) indicating that the LOD of the CM-LAMP assay in pure culture was $40 \mathrm{CFU} / \mathrm{ml}$ or $0.2 \mathrm{CFU}$ per reaction, which is $100 \times$ and $10 \times$ lower than the LOD of PCR and conventional LAMP assays, respectively. Saliva from healthy individuals was artificially spiked with $H$. pylori before DNA extraction. CM-

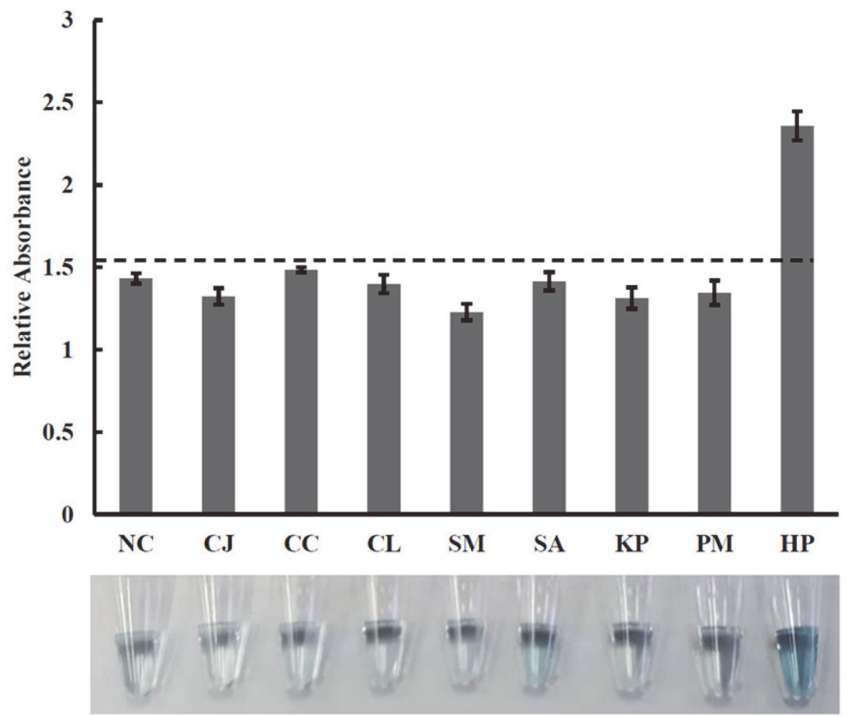

Fig. 4. The chart illustrates the specificity of the CM-LAMP assay. The upper panel is a bar chart of relative absorbance and the lower panel presents pictures of corresponding reaction tubes. DNA extracted from pure cultures of oralenteric bacteria was tested by the CM-LAMP assay. DI water was used as a negative control (NC). All experiments were done in triplicate. The standard error (SE) of the mean values of each sample was shown above each bar. The cut-off value was obtained by measuring the relative $\mathrm{OD}_{405 \mathrm{~nm}}$ of the negative control at $405 \mathrm{~nm}$, and the average absorbance and $3 \mathrm{SE}$ were calculated to establish the cut-off value illustrated as a dashed line $(\mathrm{NC}+3 \mathrm{SE}) . \mathrm{NC}=$ Negative control, $\mathrm{CJ}=$ Campybacter jejuni, $\mathrm{CC}=$ Campybacter coli, $\mathrm{CL}=$ Campybacter lari, $\mathrm{SM}=$ Streptococcus mutans, $\mathrm{SA}=$ Staphylococcus aureus, $\mathrm{KP}=$ Klebsiella pneumoniae, $\mathrm{PM}=$ Proteus mirabilis, $\mathrm{HP}=$ Helicobacter pylori. 
A

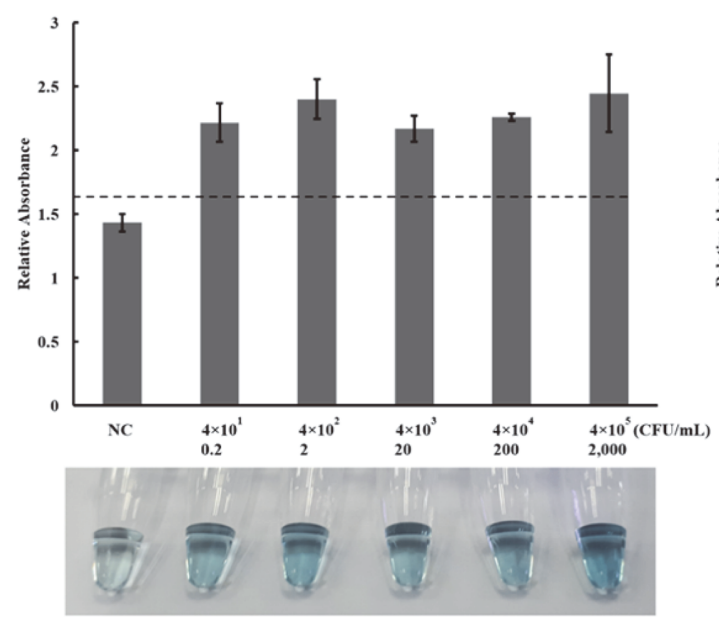

B

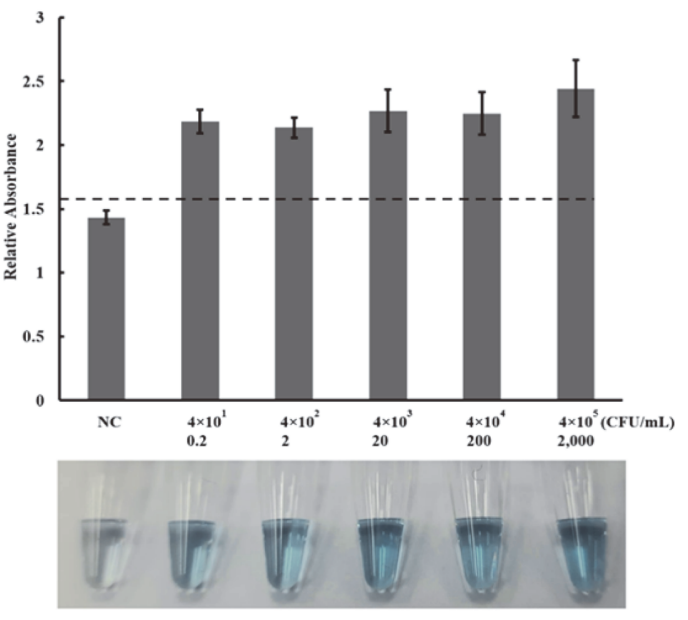

Fig. 5. The charts illustrate the sensitivity of the CM-LAMP assay in pure culture (A) and spiked saliva (B). The upper panels are bar charts of relative absorbance, the lower panels present pictures of reaction tubes. Various DNA concentrations of $H$. pylori $\left(4 \times 10^{1}\right.$ to $\left.4 \times 10^{5} \mathrm{CFU} / \mathrm{ml}\right)$ from pure cultures $(\mathbf{A})$ or spiked saliva samples $(\mathbf{B})$ were analyzed by the CM-LAMP assay. DI water or non-inoculated saliva was used as a negative control (NC). All experiments were done in triplicate. The cut-off value was obtained by measuring the relative $\mathrm{OD}_{405 \mathrm{~nm}}$ of the corresponding negative control at $405 \mathrm{~nm}$, and the average absorbance and $3 \mathrm{SE}$ were calculated to establish the cut-off value, illustrated as a dashed line (NC $+3 \mathrm{SE})$.

LAMP assay successfully detected $H$. pylori (Fig. 5B). At the end of measurement, reaction mixtures containing 0 , $0.2,2,20,200$ and $2,000 \mathrm{CFU}$ of $H$. pylori had relative absorbances of $1.43 \pm 0.05,2.18 \pm 0.09,2.14 \pm 0.08,2.27 \pm$ $0.17,2.25 \pm 0.17$, and $2.44 \pm 0.22$, respectively. In the context of a saliva matrix, the cut-off value was 1.58 , and the LOD was $40 \mathrm{CFU} / \mathrm{ml}$ or $0.2 \mathrm{CFU}$ per reaction, which is $100 \times$ lower than the LOD of PCR and conventional LAMP assays.

\section{Discussion}

In this study, newly designed primers targeting the $16 \mathrm{~S}$ rRNA gene were used for the specific detection of $H$. pylori by conventional LAMP and CM-LAMP assays. No other bacteria could produce a positive result in both LAMP assays, indicating the notable specificity (100\%) of the assays (Table 2 and Fig. 4). This was mainly due to the function of two primer pairs (inner and loop primers) that selectively annealed on particular regions of the DNA template and then produced amplicons (Table 1). Inner primers (FIP and BIP) offer auto-cycling amplification through self-priming and self-extension of stem-loop DNA products. Meanwhile, loop primers (LF and LB) bind to a nucleotide loop created by the incorporation of inner primers and facilitate the additional extension of the targeted strand [22]. In Table 3 , the better detection (10 times lower LOD) of conventional LAMP compared to PCR has been attributed to the continuously isothermal strand extension and high rate of product formation catalyzed by Bst DNA polymerase [23]. This also helped shorten operation time to less than an hour. Our conventional LAMP had the LOD of $400 \mathrm{CFU} / \mathrm{ml}$ which is approximately 10-to-100 times lower than LODs reported previously by two independent groups $\left(2 \times 10^{3}\right.$ and $\left.2 \times 10^{4} \mathrm{CFU} / \mathrm{ml}\right)[24,25]$. Although all LAMP assays were specific to the glmM gene of $H$. pylori, our conventional LAMP was more sensitive, presumably because of the larger number of amplicons produced by the action of the two additional loop primers (LF and LB) [22]. The conventional LAMP assay has several notable advantages over the PCR assay: shorter operation time, costeffective instrumentation, no requirement of post-reaction handling steps, and visible amplified products [26]. However, difficulties such as subjective interpretation (turbidity of Mg pyrophosphate and color change of HNB), inhibition of amplification (SyBr Green I), and exposure to a carcinogen (EtBr staining in gel electrophoresis) have been reported in the detection of LAMP products [27]. The multiple primers used in the LAMP reaction may increase the likelihood of primer-dimer and primer-primer hybridizations, possibly leading to false-positive results [27]. These problems reduce the feasibility of using LAMP in a routine laboratory setting. Therefore, to improve the efficiency of analysis in this study, CM-LAMP was developed by incorporating the advantages of LAMP, MNPs, and a colorimetric system. Applying an external magnetic force to MNPs enables simple isolation or concentration of target molecules. The large surface area of MNPs could provide a platform for bioreceptor immobilization for particular purposes [14]. In this work, LF primer-coupled MNPs were prepared using an initial amount of $2 \mathrm{nmol}$ of $\mathrm{NH}_{2}$-modified oligonucleotides. Additionally, a long spacer $\left(-\mathrm{C}_{12}{ }^{-}\right)$was incorporated into the primer in order to minimize the steric hindrance effect during primer immobilization on the MNP surface and primer annealing to the DNA target [20]. However, a higher amount of primers (2.5 nmol) was used in the immobilization step and possibly caused electrostatic repulsion or steric hindrance at the surface of MNPs [28], which could negatively affect immobilization efficiency (Fig. 2). The prepared LF-coupled MNPs were verified by the addition of complementary biotinylated oligonucleotides and an HRP-ABTS mixture. Results 
indicated that the coated LF primers were accessible to their complementary counterpart and a colorimetric reaction ensued. Meanwhile, blocking the MNP surface with BSA was necessary to eliminate non-specific adsorption of complementary nucleotide sequences as well as false-positive signals (Fig. 3) [29]. The background absorbance observed when LF primer or complementary oligonucleotide was absent was probably due to ABTS oxidation catalyzed by the MNPs (Fig. 3). The MNPs were made of magnetite $\left(\mathrm{Fe}_{3} \mathrm{O}_{4}\right)$ which harbors peroxidaselike activity [30]. Our CM-LAMP assay was successful in selectively amplifying the target region and giving a colorimetric reaction that aided result interpretation (Fig. 4). This outcome indicated that modified FIP remained functional in primer annealing and strand-extension during the LAMP reaction and interacted with NA-HRP during colorimetric detection [31-33]. The NA tag was used because it could generate lower nonspecific binding than avidin and streptavidin. The biotin-binding activity of NA was about $14 \mu \mathrm{g} / \mathrm{mg}$ of protein which is close to the theoretical maximum activity [34]. The green color of the ABTS ${ }^{++}$product was stable for an hour and could be measured spectrophotometrically [35]. The establishment of cut-off value was done by negative samples to exclude all background absorbance.

Our CM-LAMP assay was specific solely to $H$. pylori isolates, while other microorganisms including closely related ones and plausible contaminants gave absorbances below the cut-off value (Fig. 4). From LOD results, the CM-LAMP assay was between 10 and 100 times more sensitive in the detection of pure $H$. pylori culture $(40 \mathrm{CFU} / \mathrm{ml})$ in comparison with the conventional LAMP and PCR assays, respectively (Fig. 5A). It has been reported that saliva and vomitus samples collected from patients contained $10^{2}$ to $10^{3} \mathrm{CFU} / \mathrm{ml} \mathrm{H}$. pylori [36, 37]. The CMLAMP assay achieved comparable LODs (100 times lower than conventional LAMP and PCR assays) when spiked saliva samples were tested (Fig. 5B). This indicated that mucin, a LAMP inhibitor in saliva, did not interfere with the analytical efficiency of our designed platform [38]. Many colorimetric LAMP assays have been developed through combination with other analytical approaches to increase their detectability. These techniques, which include LAMP-enzyme linked immunosorbent assay (LAMP-ELISA) [13], magneto reverse transcription LAMP-based chemiluminescence assay (RT-LAMP-CL) [39], magneto LAMP-based electrochemical assay (ECLAMP) [40], and probe-specific LAMP magneto assay [31], have employed a two-step detection approach for amplifying the target gene and then hybridizing to the specific capture probes coated on the surface of magnetic materials or a microtiter plate. Our CM-LAMP assay offers a novel platform using modified LF and FIP primers which enables simultaneous solid-phase amplification, hybridization, and amplicon labeling. This not only reduces the operation time but also provides more efficient strand extension-mediated amplicon capture between the labeled LAMP product and MNPs. The LOD of the LAMP-ELISA assay for Salmonella enterica ser. Paratyphi and serogroup D has been reported with the LOD of 10 and $10^{3} \mathrm{CFU} / \mathrm{ml}$ in spiked blood and spiked meat, respectively $[13,32]$. The high sensitivity and specificity of the CM-LAMP assay affirm the feasibility of using this technique for noninvasive $H$. pylori detection in saliva samples.

In conclusion, we presented a non-invasive, rapid, and highly sensitive platform of a CM-LAMP assay to selectively detect $H$. pylori in saliva samples. This technique combines many advantages of the LAMP assay, magnetic nanoparticles, and a colorimetric system to attain high sensitivity ( 1 CFU per reaction) and specificity. Exceptionally, our platform could provide a complete analysis in less than three hours and can also be applied to other target genes or microorganisms. This method could serve as a new approach for developing an automatic system for molecular diagnostics.

\section{Acknowledgments}

The authors appreciate the generous advice throughout our study of Prof. Dr. Varaporn Vuddhakul and are grateful to Mr. Thomas Duncan Coyne for his assistance with the English. This research was funded by the National Research Council of Thailand (NRCT) and Thailand Science Research and Innovation (TSRI) through the Royal Golden Jubilee PhD Program (Grant No. PHD/0224/2558), from the Thailand Research Fund (TRF) through the Research Grant for New Scholar (Grant No. MRG5580110), and from Prince of Songkla University through the Scholarship for Outstanding GPA and research grant (MET6302042S).

\section{Conflict of Interest}

The authors have no financial conflicts of interest to declare.

\section{References}

1. Moller H, Heseltine E, Vainio H. 1995. Working group report on schistosomes, liver flukes and Helicobacter pylori. Int. J. Cancer 60: $587-589$

2. Brown LM. 2000. Helicobacter pylori: epidemiology and routes of transmission. Epidemiol. Rev. 22: 283-297.

3. Sabbagh P, Mohammadnia-Afrouzi M, Javanian M, Babazadeh A, Koppolu V, Vasigala VR, et al. 2019. Diagnostic methods for Helicobacter pylori infection: ideals, options, and limitations. Eur. J. Clin. Microbiol. Infect. Dis. 38: 55-66.

4. Uotani T, Graham DY. 2015. Diagnosis of Helicobacter pylori using the rapid urease test. Ann. Transl. Med. 3: 9.

5. Osaki T, Mabe K, Hanawa T, Kamiya S. 2008. Urease-positive bacteria in the stomach induce a false-positive reaction in a urea breath test for diagnosis of Helicobacter pylori infection. J. Med. Microbiol. 57: 814-819.

6. Patel SK, Pratap CB, Jain AK, Gulati AK, Nath G. 2014. Diagnosis of Helicobacter pylori: what should be the gold standard? World J. Gastroenterol. 20: 12847-12859.

7. Azevedo NF, Almeida C, Cerqueira L, Dias S, Keevil CW, Vieira MJ. 2007. Coccoid form of Helicobacter pylori as a morphological manifestation of cell adaptation to the environment. Appl. Environ. Microbiol. 73: 3423-3427.

8. Shimoyama T. 2013. Stool antigen tests for the management of Helicobacter pylori infection. World J. Gastroenterol. 19: 8188-8191.

9. Miftahussurur M, Yamaoka Y. 2016. Diagnostic Methods of Helicobacter pylori infection for epidemiological studies: critical importance of indirect test validation. Biomed. Res. Int. 2016: 4819423. 
10. Kabir S. 2004. Detection of Helicobacter pylori DNA in feces and saliva by polymerase chain reaction: a review. Helicobacter 9: 115-123.

11. Monteiro L, Bonnemaison D, Vekris A, Petry KG, Bonnet J, Vidal R, et al. 1997. Complex polysaccharides as PCR inhibitors in feces: Helicobacter pylori model. J. Clin. Microbiol. 35: 995-998.

12. Notomi T, Okayama H, Masubuchi H, Yonekawa T, Watanabe K, Amino N, et al. 2000. Loop-mediated isothermal amplification of DNA. Nucleic Acids Res. 28: E63.

13. Ravan H, Yazdanparast R. 2012. Development and evaluation of a loop-mediated isothermal amplification method in conjunction with an enzyme-linked immunosorbent assay for specific detection of Salmonella serogroup D. Anal. Chim. Acta. 733: 64-70.

14. Safarik I, Safarikova M. 2009. Magnetic nano-and microparticles in biotechnology. Chem. Pap. 63: 497-505.

15. Jain KK. 2005. Nanotechnology in clinical laboratory diagnostics. Clin. Chim. Acta 358: 37-54.

16. Lage AP, Godfroid E, Fauconnier A, Burette A, Butzler JP, Bollen A, et al. 1995. Diagnosis of Helicobacter pylori infection by PCR: comparison with other invasive techniques and detection of cagA gene in gastric biopsy specimens. J. Clin. Microbiol. 33:2752-2756.

17. Whitmire JM, Merrell DS. 2012. Successful culture techniques for Helicobacter species: general culture techniques for Helicobacter pylori. Methods Mol. Biol. 921:17-27.

18. Jangpatarapongsa K, Polpanich D, Yamkamon V, Dittharot Y, Peng-On J, Thiramanas R, et al. 2011. DNA detection of chronic myelogenous leukemia by magnetic nanoparticles. Analyst 136: 354-358.

19. Thiramanas R, Jangpatarapongsa K, Tangboriboonrat P, Polpanich D. 2013. Detection of Vibrio cholerae using the intrinsic catalytic activity of a magnetic polymeric nanoparticle. Anal. Chem. 85: 5996-6002.

20. Jansaento W, Jangpatarapongsa K, Polpanich D, Wonglumsom W. 2016. Detection of Campylobacter DNA using magnetic nanoparticles coupled with PCR and a colorimetric end-point system. Food Sci. Biotechnol. 25: 193-198.

21. Zhu X, Zhou X, Xing D. 2012. Nano-magnetic primer based electrochemiluminescence-polymerase chain reaction (NMPE-PCR) assay. Biosens. Bioelectron. 31: 463-468.

22. Nagamine K, Hase T, Notomi T. 2002. Accelerated reaction by loop-mediated isothermal amplification using loop primers. Mol. Cell. Probes 16: 223-229.

23. Gadkar VJ, Goldfarb DM, Gantt S, Tilley PA. 2018. Real-time detection and monitoring of loop mediated amplification (LAMP) reaction using self-quenching and de-quenching fluorogenic probes. Sci. Rep. 8: 5548.

24. Minami M, Ohta M, Ohkura T, Ando T, Torii K, Hasegawa T, et al. 2006. Use of a combination of brushing technique and the loopmediated isothermal amplification method as a novel, rapid, and safe system for detection of Helicobacter pylori. J. Clin. Microbiol. 44: 4032-4037.

25. Bakhtiari S, Alvandi A, Pajavand H, Navabi J, Najafi F, Abiri R. 2016. Development and diagnostic evaluation of loop-mediated isothermal amplification using a new gene target for rapid detection of Helicobacter pylori. Jundishapur J. Microbiol. 9: e28831.

26. Mori Y, Notomi T. 2009. Loop-mediated isothermal amplification (LAMP): a rapid, accurate, and cost-effective diagnostic method for infectious diseases. J. Infect. Chemother. 15: 62-69.

27. Wong YP, Othman S, Lau YL, Radu S, Chee HY. 2018. Loop-mediated isothermal amplification (LAMP): a versatile technique for detection of micro-organisms. J. Appl. Microbiol. 124: 626-643.

28. Dugas V, Elaissari A, Chevalier Y. 2010. Surface sensitization techniques and recognition receptors immobilization on biosensors and microarrays, pp. 47-134. Recognition receptors in biosensors, Ed. Springer.

29. Corgié SC, Kahawong P, Duan X, Bowser D, Edward JB, Walker LP, et al. 2012. Self-assembled complexes of horseradish peroxidase with magnetic nanoparticles showing enhanced peroxidase activity. Adv. Funct. Mater. 22: 1940-1951.

30. Gao L, Zhuang J, Nie L, Zhang J, Zhang Y, Gu N, et al. 2007. Intrinsic peroxidase-like activity of ferromagnetic nanoparticles. Nat. Nanotechnol. 2: 577-583.

31. Najian AN, Foo PC, Ismail N, Kim-Fatt L, Yean CY. 2019. Probe-specific loop-mediated isothermal amplification magnetogenosensor assay for rapid and specific detection of pathogenic Leptospira. Mol. Cell. Probes 44: 63-68.

32. Ravan H, Yazdanparast R. 2013. Loop region-specific oligonucleotide probes for loop-mediated isothermal amplification-enzymelinked immunosorbent assay truly minimize the instrument needed for detection process. Anal. Biochem. 439: 102-108.

33. Liu Z-K, Zhang Q-Y, Yang N-N, Xu M-G, Xu J-F, Jing M-L, et al. 2019. Rapid and sensitive detection of salmonella in chickens using loop-mediated isothermal amplification combined with a lateral flow dipstick. J. Microbiol. Biotechnol. 29: 454-464.

34. Marttila AT, Laitinen OH, Airenne KJ, Kulik T, Bayer EA, Wilchek M, et al. 2000. Recombinant NeutraLite avidin: a non-glycosylated, acidic mutant of chicken avidin that exhibits high affinity for biotin and low non-specific binding properties. FEBS Lett. 467: 31-36.

35. Matsuda H, Tanaka H, Blas B, Nosenas J, Tokawa T, Ohsawa S. 1984. Evaluation of ELISA with ABTS, 2-2'-azino-di-(3-ethylbenzthiazoline sulfonic acid), as the substrate of peroxidase and its application to the diagnosis of schistosomiasis. Jpn. J. Exp. Med. 54: 131-138.

36. Yee JKC. 2017. Are the view of Helicobacter pylori colonized in the oral cavity an illusion? Exp. Mol. Med. 49 : e397.

37. Graham D, Opekun A, Osato M, El-Zimaity H, Lee C, Yamaoka Y, et al. 2004. Challenge model for Helicobacter pylori infection in human volunteers. Gut 53: 1235-1243.

38. Jiang YS, Bhadra S, Li B, Wu YR, Milligan JN, Ellington AD. 2015. Robust strand exchange reactions for the sequence-specific, realtime detection of nucleic acid amplicons. Anal. Chem. 87: 3314-3320.

39. Wang J, Lu P, Yan J, Zhang Y, Huang L, Ali Z, et al. 2016. Rapid and sensitive detection of RNA viruses based on reverse transcription loop-mediated isothermal amplification, magnetic nanoparticles, and chemiluminescence. J. Biomed. Nanotechnol. 12: 710-716.

40. Bartosik M, Jirakova L, Anton M, Vojtesek B, Hrstka R. 2018. Genomagnetic LAMP-based electrochemical test for determination of high-risk HPV16 and HPV18 in clinical samples. Anal. Chim. Acta 1042: 37-43. 